\title{
Investigation of Unstable Failure Potential of a Shear Slip Using DEM at an Underground Mine
}

\author{
Xu Ma' and Ping Zhang ${ }^{2}$
}

\begin{abstract}
Geological structures and discontinuities subjected to the perturbations posed by mining operations in underground mining can be re-activated and cause fault-slip rockbursts. This study investigates geomechanical stability in terms of shear slip behavior along discontinuities using 3DEC with focusing on sudden changes of shear stress and shear displacement. A direct shear test is performed using a continuously yielding joint model to examine the evolution of shear stress and shear displacement on this joint. Further, this continuously yielding joint model is applied in major discontinuities of an underground mine to examine whether an unstable shear slip behavior exists, which is represented by a significant shear stress decrease and a shear displacement increase. By referring to geological mapping of this mine, four cases are developed and each case is set up with one type of major discontinuities with identically simulated mining operations. Results imply that the amplitude of shear stress decrease and shear displacement increase along discontinuities substantially increases with the depth due to higher virgin stresses and mining-induced stresses at greater depths. The discontinuity parallel to the interface between footwall and orebody is the least safe case and subjects to the largest potential of triggering seismic events.
\end{abstract}

Keywords: Shear slip behavior, Unstable failure, Mining-induced seismicity, Continuously yielding joint model, DEM.

${ }^{1}$ Division of Mining and Geotechnical Engineering, Luleå University of Technology, Sweden.

2 Division of Mining and Geotechnical Engineering, Luleå University of Technology, Sweden.

Article Info: Received: April 12, 2021. Revised: April 20, 2021.

Published online: May 30, 2021. 


\section{Introduction}

Better understanding of rock mass failure caused by subsurface operations is of importance to mitigate geohazards in underground mining. The stability of rock masses is progressively weakened and sometimes abruptly lost by excavation and extraction in mining, thereby leading to considerable incidents of geohazards. With the increasing depth of operations in mining, failure of rock masses is more likely triggered by the nearby discontinuities. Such failures can occur in a gradual and nonviolent manner, which is referred to as stable or controlled failure. This type of failure and damage is closely correlated with the progress of advancing mining and then the hazards can be effectively mitigated by halting mining productions. In contrast, sometimes damage can be triggered to happen in a rapid and violent manner with a large amount of stored energy released in a very short time period, which is referred to as unstable or uncontrolled failure (Salamon, 1970; Wiles, 2002; $\mathrm{Gu}$ and Ozbay, 2014). It is difficult to forecast unstable failures and therefore tremendous loss is caused by them due to the lack of precursory alerts. Seismic events, appearing to be temporally and spatially correlated with these unstable failures in many cases, can be used as reliable precursory indicators to these unstable failures in seismic hazards mitigation for mining (Young and Maxwell, 1992; Trifu et al., 1995; Malek et al., 2008; Ma et al., 2018). A seismic event is a transient earth motion caused by a sudden release of potential or stored strain energy in the rock mass (Ma et al., 2018; Blake and Hedley, 2003). A fault-slip event is triggered as slippage suddenly occurs along a geological weakness plane. If the fault-slip event causes any damage or rockfall to an underground excavation, the event is called a damaging fault-slip event and the accompanying damage occurred in a sudden and violent manner is defined as a rockburst. Accordingly, it is critical to make a good use of tools to forecast rockbursting potential of geological structures/discontinuities.

The concept of Local System Stiffness (LSS) was initially used to analyze pillar stabilities (Salamon, 1970; Blake and Hedley, 2003). Failure stability characterization has been studied extensively, but stable- and unstable- failures cannot be clearly distinguished from these concepts as they are based on terms "strength" and "failure" (Gu and Ozbay, 2014a). Numerical studies with LSS also showed that the stability is governed by the relative stiffness of the discontinuity and its wall rocks in pillars (Gu and Ozbay 2014b, 2015). Moreover, it is suggested that LSS can be used as a criterion to differentiate loading systems as soft loading systems and stiff loading systems to provide a tool for taking account into unstable shear failure (Gu and Ozbay 2014b, 2015; Xu and Cai, 2017). Rice (1983) incorporated LSS into the study of fault slip and earthquake instabilities. It is shown in Figure 1 that during shear slip the stiffness of the fault controls if the failure occurs in a stable or unstable manner (Manouchehrian and Cai, 2016). 


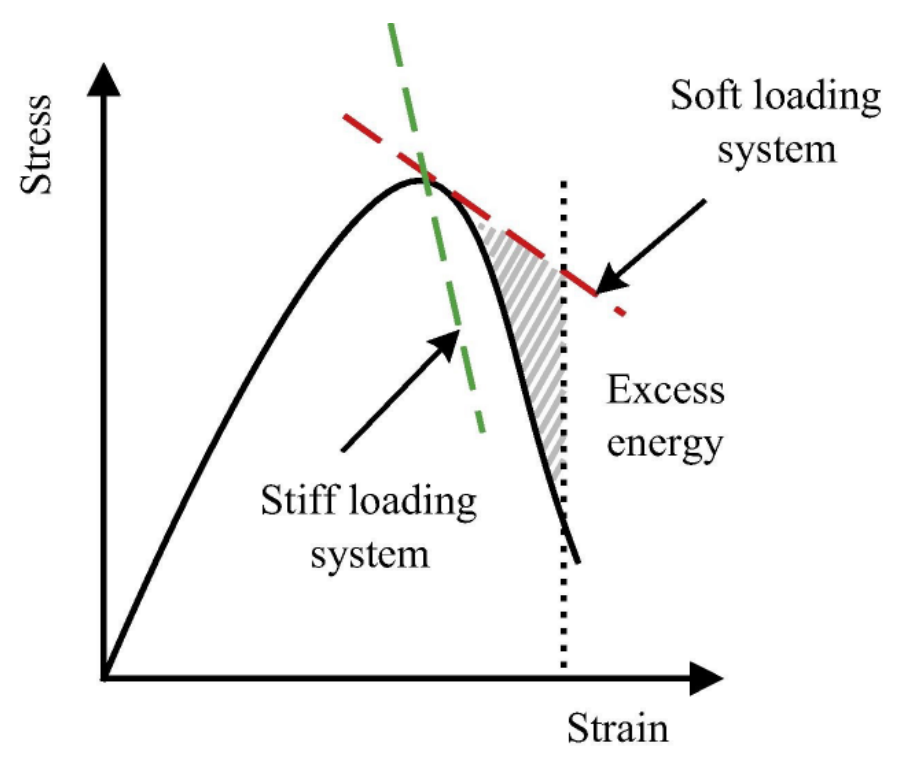

Figure 1: Illustration of the stiffness concept for the stability of rock material (Manouchehrian and Cai, 2016). The solid line represents the characteristic stress-strain behaviour of a rock specimen. The dashed lines represent the loading system stiffness. When stress exceeds the ultimate strength of the rock specimen, failure is stable when the post-peak stiffness of the specimen is smaller in absolute value than the loading system stiffness (the green line). Otherwise, the failure is unstable, shown as the soft loading system condition (the red line).

Previous studies summarized that rockbursts tend to occur in underground hard rock mines when a volume of brittle rock is stressed beyond its strength by a comparatively soft loading system (Salamon, 1970; Cook, 1965; Rice, 1983; Blake and Hedley, 2003; Garvey, 2013). Although the loading stiffness concept has been well established and recognized as a reasonable analysis approach to assess whether failures would occur in a stable or unstable manner, there are still significant gaps to accurately characterize the failure stability due to the challenge of adequately representing and determining the post-failure stiffness of rock masses and the local mine stiffness in a specific mining layout. Due to complex mining geometry and multiple excavations, it becomes extremely difficult to use any closed-form or approximate solutions.

Researchers over the past several decades have supplemented the study of unstable failures through the application of various numerical modelling techniques with mixed success, but the studied fields have been limited to coal mining (Aglawe, 2000; Li and Heasley, 2015). Therefore, there is a need to explore the capabilities of the existing numerical modelling programs in identifying not only the possibility of failure but also the stability of these failures so that measures can be taken against 
rockburst events for a given mine settings. It is found that the Kiirunavaara Mine is experiencing more mining-induced seismicity due to the increasing depth of mining operations and massive mining method (sublevel caving). These mining activities inevitably perturb and are likely to activate the structures in this mine, leading to shear slip behaviors of rock masses and seismic events in the vicinity of structures. Recent forensic investigations at the Kiirunavaara Mine showed that several damaging events are fault-slip events and have larger magnitudes. When mining at a great depth, discontinuities become subjected to the mining activities as large driving forces induced by mining greatly change the stress conditions and weaken the properties of discontinuities, resulting in sudden slip failure along the discontinuities. However, it is still not clear how to evaluate the slip burst potential of the discontinuities. Assuming that the discontinuity is a critical factor leading to the slip burst, a comparison of instability between different geometries of discontinuities can provide a reference to underground mining. The goal of this study was focused on developing a numerical methodology with the loading stiffness concept to assess the slip burst potential of discontinuities for underground mines.

\section{Data and methods}

\subsection{The mine and seismicity}

The Kiirunavaara Mine, owned and operated by LKAB, has been in operation since 1898 and produces iron ore. In mid-1950, the mine started a transition to underground mining and passed to only underground mining in 1962. It is one of the world's largest underground mines. The mining method used in the mine is sublevel caving. The mine has been regarded as seismically active after it has experienced several larger seismically induced rock falls since 2007 (Dahnér et al., 2012). More than 1000 seismic events per day have been recorded in the whole mine during recent years. Most of the damaging seismic events investigated in block 33/34 of the mine from 2008 to 2013 were categorized as fault-slip type (Vatcher et al., 2014; Nordström et al., 2017). In the early history of underground mining in Kiirunavaara, the main stability problems occurred within the drift were gravity falls. The overall stability in recent years, however, is governed by the high stresses and mining-induced seismic events due to the great depth of mining operations. With the increasing depth of mining operations and involving complex geological discontinuities, it is anticipated that seismic activities will be active in long term. Five seismic events were captured from 2014 to 2016 and most of them were fault slip type events according to the ratio of Es/Ep. It is generally recognized that a fault slip type event is with the ratio of Es/Ep lager than 10. In addition, mining operations perturb the regional stress field, activating joints and faults that used to be dormant. These seismic events ranged from $1000 \mathrm{~m}$ to $1200 \mathrm{~m}$ in depth, which was also the main levels of blocks with active mining operations in recent years. At Kiirunavaara Mine, the orebody extends as long as about 4,000 m, strikes nearly north-south, and dips $55-60^{\circ}$ toward the east. The total lateral extension of orebody 
is more than $4 \mathrm{~km}$ and the thickness of orebody varies from 0 to over $200 \mathrm{~m}$. The width of the orebody is $80 \mathrm{~m}$ in average (Sjöberg et al., 2012; Svartsjaern et al., 2016).

\subsection{Geological settings}

The geology of the Kiruna area is characterized by a succession of volcanic and metasedimentary rocks that are deposited on top of an Archean gneissic granitoid basement. The footwall of the Kiirunavaara orebody consists of intermediate volcanic to plutonic rocks. The orebody consists in detail of several silvers of ore that are semi-continuous with each other. The ore is emplaced between the intermediate volcanic rocks of the footwall and the acid volcanic rocks of the hanging wall. The contacts are mostly sharp, but typically irregular and complex with breccias and magnetite veining are found in detail. The hanging wall rock consists of a succession of mostly pyroclastic rhyodacitic-rhyolitic deposit and these rocks carry variable fragments including iron ore and footwall-type porphyries.

A series of geological survey was performed for better understanding geological structures and their possible influences on geomechanical stability affected by mining operations. The structure mapping is summarized by block, level, and important geological features and the major factures are ubiquitous in Kiirunavaara mine. According to the geological investigations around Block 30, 34 and 38 in levels $1079-1137 \mathrm{~m}$, the rock mass within this block accommodates roughly 6500 major fractures/joints, which were broadly divided into multiple groups by their strike-dipping directions. Four dominant groups were subdivided into: 1. Near-EW striking, dipping intermediately steep $\left(50-80^{\circ}\right)$ to the south; 2 . Near-N-S to NW striking, dipping steeply $\left(60-90^{\circ}\right)$ to the east; 3 . Near-E-W striking with relatively steep dips $\left(60-90^{\circ}\right)$ to the North; 4 . Near-N-S striking, dipping steeply $\left(70-90^{\circ}\right)$ to the West. It has been concluded by previous studies that the discontinuities parallel with the dip direction weaken the stability most during mining operations. This group of discontinuities is described as Near-N-S to NW striking, dipping steeply $\left(60-90^{\circ}\right)$ to the east.

\section{Numeral modeling for analyzing instability caused by discontinuities}

\subsection{Continuously yielding model}

The commercial software package 3DEC (2016), developed by Itasca, was employed in this study to model and evaluate unstable failures along discontinuities in rock masses of Kiirunavaara Mine. 3DEC was designed based on distinct element method for discontinuum modeling. An assemblage of discrete blocks mimics the discontinuous media such as jointed rock mass. Correspondingly, discontinuities in rock masses are represented by boundary interactions, which can be assigned with joint behaviors. 
In order to generalize practical engineering problems using a theoretical model with empirical studies, the continuously yielding (CY) joint model was developed by Cundall and Hart (1984) to concisely reflect the internal mechanism of progressive degradation of shear strength and the corresponding mechanism of shear failure of joints (Cundall and Lemos, 1990). In addition, the concept of bounding surface was imported for considering continuous hysteretic damping for dynamic simulations. Compared with other joints models such as Mohr-Coulomb joint model, the merit of CY joint model is that it takes into account non-linear behaviors, including joint shearing damage, stiffness evolution with changing normal stress, and dilation angle reduction with shear displacement, so as to simulate the practical post-peak behavior of rock joints (Sandstrom, 2003). The evolution of shear stiffness of rock joints could be inferred and tracked by observing change of residual shear strength and shear displacement of the joints. The relations between shear stress and shear displacement display a trend that the practical shear strength tends to evolve toward an objective shear strength, which keeps dropping until reaching an ultimate residual shear strength. The decrease process of practical shear strength with approaching the objective shear strength, associated with the growth of shear displacement, forms a post-peak softening behavior of rock discontinuities. The normal stress and shear displacement mutually determine the objective shear strength and it has been proved that the objective shear strength is positively correlated with the applied normal stress. An example of applying CY joint model in assessing rock-fault stability affected by seismicity was studied (Cundall and Lemos, 1990).

\subsection{Constitutive model verification}

To verify the CY joint model and the modelling technique, a direct shear test was simulated. In this direct shear test, a smaller block was placed on the top of a larger block, which was fixed on the ground (Figure 2a,2b). The top block is a block of cube shape with a side length of $0.2 \mathrm{~m}$. The bottom block is of cuboid shape with a rectangular shape in the cross section. The height of the bottom block is $0.2 \mathrm{~m}$, and the length as well as the width of the bottom block is $0.6 \mathrm{~m}$. 
(a)

Compressive load $30 \mathrm{MPa}$
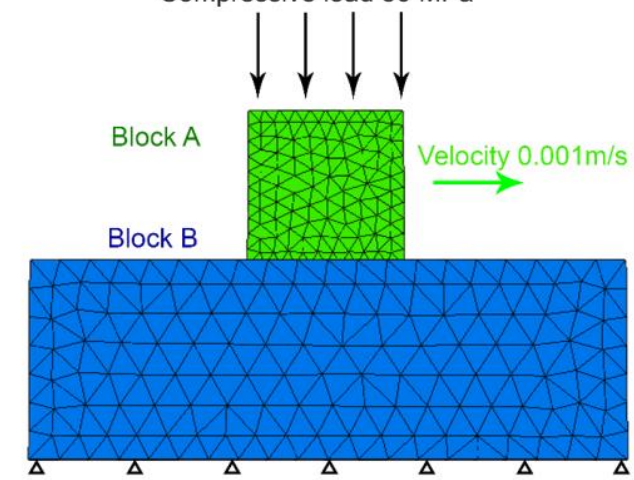

(c)

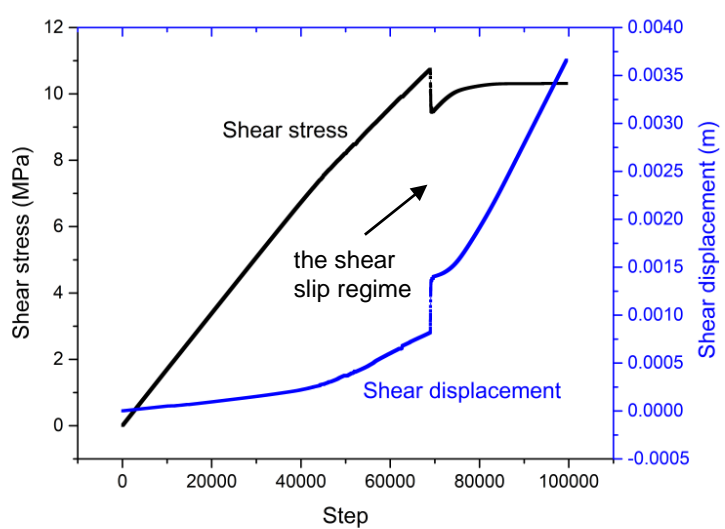

(b)

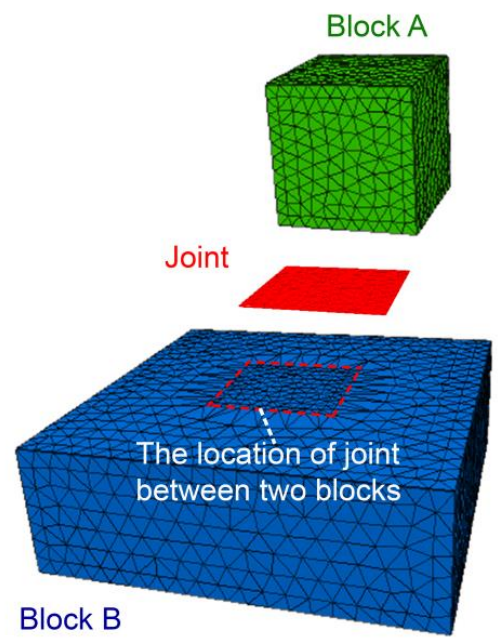

(d)

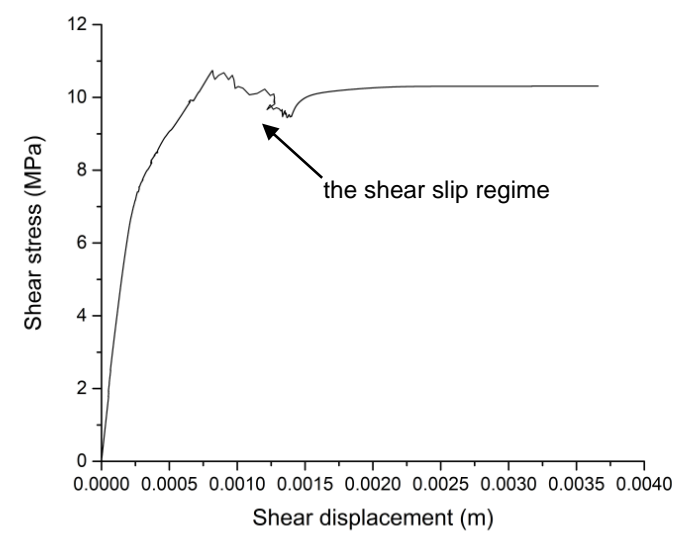

Figure 2: (a) The direct shear test setup; (b) the structure of blocks with a joint; (c) The direct shear test result of shear stress-shear displacement; (d) shear stress vs shear displacement.

The top block was initially placed on the center of the top surface of the bottom block. Normal stress was applied on the top of the smaller block. A constant velocity of $0.001 \mathrm{~m} / \mathrm{s}$ along the horizontal direction was applied on the top block to exert shear loading on the interface. The frictional interface between these two blocks was assigned the CY joint model (Figure 2a). The average shear stress and shear displacement of the frictional interface were recorded and computed.

To verify the viability of using CY joint model for the discontinuities of Kiirunavaara Mine, the actual materials properties of rock were assigned to the top block. The bottom block was assigned with very high bulk modulus and shear modulus in order to prevent displacement from the bottom block. Properties of the CY joint model, as listed in Table 1, were selected to simulate the interface according to parameter studies. 
Table 1: Parameters used for the CY joint model in the direct shear test.

\begin{tabular}{|c|c|c|}
\hline Joint property & Unit & Value \\
\hline Joint normal stiffness & $\mathrm{GPa} / \mathrm{m}$ & 110 \\
\hline Joint shear stiffness & $\mathrm{GPa} / \mathrm{m}$ & 90 \\
\hline Joint normal stiffness exponent & & 0 \\
\hline Joint shear stiffness exponent & & 0 \\
\hline Joint basic friction angle & Degree & 25 \\
\hline Joint initial friction angle & Degree & 65 \\
\hline Roughness parameter & mm & 0.1 \\
\hline
\end{tabular}

By adjusting the moduli of the top block and remaining other parameters unchanged (Table 2), the whole system stiffness varied and resulted in multiple scenarios of loading systems including soft-, moderate- and stiff- loading system, as defined by the difference between the stiffness of the top block and the bottom block. The relationship, in different loading systems, between the average shear stress and the average shear displacement of the interface between the top block and the bottom block was examined and is presented in Figure 2. The result exhibits a rapid increase in shear displacement and a sudden decrease in shear stress (Figure 2c) during the shear slip regime that starts at the same step in Figure 2c. After examining the corresponding response of shear stress versus shear displacement in Figure 2d, we found that the shear slip regime corresponded to the post-peak duration when the shear stress decreased with the increasing shear displacement in a fluctuated pattern before returning to a later stable stage. That said, post-peak began at the step when the abrupt change initiated in shear stress and shear displacement. The characteristic of CY joint model proved that this model is capable of describing unstable shear slip behavior of discontinuities, where the sudden, rapid change in shear stress and shear displacement is induced as a reflection of unstable failure at the beginning of post-peak response of discontinuities.

Table 2: Parameters for the blocks in the direct shear test.

\begin{tabular}{|c|c|c|c|c|c|}
\hline \multicolumn{3}{|c|}{ Top block } & \multicolumn{3}{c|}{ Bottom block } \\
\hline Density & Bulk modulus & Shear modulus & Density & Bulk modulus & Shear modulus \\
\hline $2800 \mathrm{~kg} / \mathrm{m}^{3}$ & $0.60 \mathrm{GPa}$ & $0.41 \mathrm{GPa}$ & $4700 \mathrm{~kg} / \mathrm{m}^{3}$ & $1190 \mathrm{GPa}$ & $820 \mathrm{GPa}$ \\
\hline
\end{tabular}




\subsection{Mine-scale conceptual numerical models}

\subsubsection{Base model setup}

A three-dimensional mine-scale conceptual model, built in 3DEC, was constructed to investigate the shear slip responses of rock discontinuities to mining productions for the Kiirunavaara Mine. In order to save computational resources, only main geological structures were represented with certain simplifications. A truncated geometric system was used considering that distribution of major blocks is almost symmetric in north-south direction. The thickness of orebody was set up as $80 \mathrm{~m}$, which is an average value of a series of varying thickness. In addition, each sublevel excavation of mining operations on the orebody was defined as $30 \mathrm{~m}$ in height based on engineering applications. Major blocks, including hanging wall, orebody, and footwall, were separated by discontinuities and each block was assigned with insitu parameters.

The overall dimensions of the model followed the in-situ conditions of Kiirunavaara mine and are shown in Figure 3. Production drifts and ore passes were not incorporated into the model for the simplicity fashion. In this model, the depth ranged from the ground surface to $1700 \mathrm{~m}$ level, the range in east-west direction was set up as $1500 \mathrm{~m}$, and the north-south direction spanned $1800 \mathrm{~m}$ including these three major blocks. Four side surfaces were constrained along directions that were perpendicular to these surfaces. The bottom surface was fixed at all directions. The top surface was applied with normal stress following the equation (1). The in-situ stresses applied in the numerical model were based on the equations proposed and are listed in the below equation,

$$
\begin{gathered}
\sigma_{x}=2.22+0.037 z \\
\sigma_{y}=1.74+0.029 z \\
\sigma_{z}=1.68+0.028 z
\end{gathered}
$$

where $z$ represents the depth below ground surface, $\sigma_{x}$ is the stress in east-west direction, $\sigma_{y}$ represents the stress in north-south direction, and $\sigma_{z}$ is stress in the depth direction. 


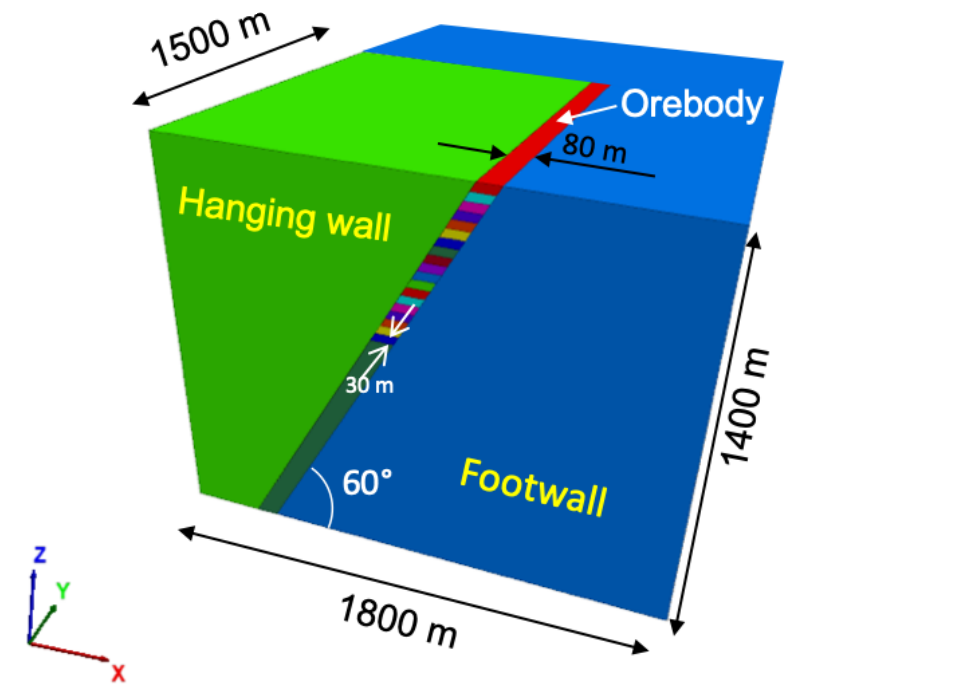

Figure 3: The 3DEC model shows the simplified subsurface structures. The width of the Kiirunavaara ore body is roughly $80 \mathrm{~m}$. Each excavation of mining operations is mimicked by sequentially removing one block $(30 \mathrm{~m}$ thickness) each time toward a deeper depth.

Mining the upper part (depth 0-300 m) of the orebody was simulated. The mined depth was equally divided into 10 horizontal sub-levels along the depth direction. The thickness of each sub-level was $30 \mathrm{~m}$ and the width as well as length were the same as the orebody. In the simulation of 3DEC modeling, each sub-level was removed and then the modeling was run until achieving a new balance state, yielding results of the model response to each mining excavation.

Gradient mesh was used for ensuring the accuracy and improving the computing efficiency. Zone sizes and aspect ratios were minimized near the excavated orebody boundary and gradually increased outwards. A series of monitoring points were set up along a line that was parallel with the discontinuity set, based on their relative distances to the discontinuity set. Details of these monitoring points are shown in figures of the section of each case.

\subsubsection{Mechanical parameters}

The rock properties of hanging wall, orebody and footwall used in the numerical simulation were originally from a previous study but adjusted after trial numerical tests (Sandstrom, 2003). The rock properties of hanging wall is assumed as equivalent to the properties of footwall, as listed in Table 3. An elastic constitutive model was assigned for rock in hanging wall and footwall as well as the ore. 
Table 3: Rock parameters used in this study.

\begin{tabular}{|c|c|c|c|}
\hline & $\begin{array}{c}\text { Density } \\
\left(\mathbf{k g} / \mathbf{m}^{\mathbf{3}}\right)\end{array}$ & $\begin{array}{c}\text { Bulk modulus } \\
(\mathbf{G P a})\end{array}$ & $\begin{array}{c}\text { Shear modulus } \\
(\mathbf{G P a})\end{array}$ \\
\hline Footwall & 2800 & 33 & 20 \\
\hline Orebody & 4700 & 21 & 13 \\
\hline Hanging wall & 2800 & 33 & 20 \\
\hline
\end{tabular}

The CY joint model was engaged to simulate mechanical behaviors of discontinuities. The parameters of CY joint model are listed in Table 4. Other interfaces that delineated the footwall, orebody and hanging wall contacts were assigned as elastic joint model.

Table 4: Parameters for discontinuities used in the conceptual mine-scale models.

\begin{tabular}{|c|c|c|}
\hline Joint property & Unit & Value \\
\hline Joint normal stiffness & $\mathrm{GPa} / \mathrm{m}$ & 50 \\
\hline Joint shear stiffness & $\mathrm{GPa} / \mathrm{m}$ & 50 \\
\hline Joint normal stiffness exponent & 0 & 0 \\
\hline Joint shear stiffness exponent & 0 & 0 \\
\hline Joint basic friction angle & $\circ$ & 25 \\
\hline Joint initial friction angle & $\circ$ & 45 \\
\hline Roughness parameter & $\mathrm{mm}$ & 0.1 \\
\hline
\end{tabular}

\subsubsection{Simulation schemes with various discontinuities setup}

Discontinuities in the rock mass of Kiirunavaara Mine could be categorized as 4 groups, as aforementioned. Four numerical models were constructed so as to investigate the effect of mining-induced stress change on the stability of each group of discontinuities alone. Each model therefore was featured by a major discontinuity or a major set of discontinuity. Details of these discontinuity groups are listed in Table 5. The geometric models for Case A, Case B, Case C and Case D are shown in Figure 4. 
(a)

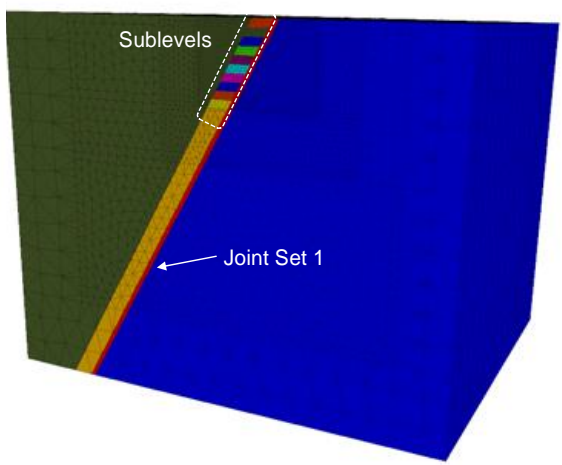

(c)

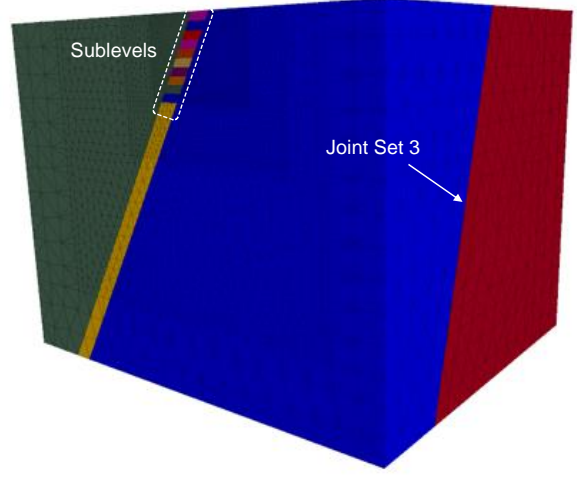

(b)

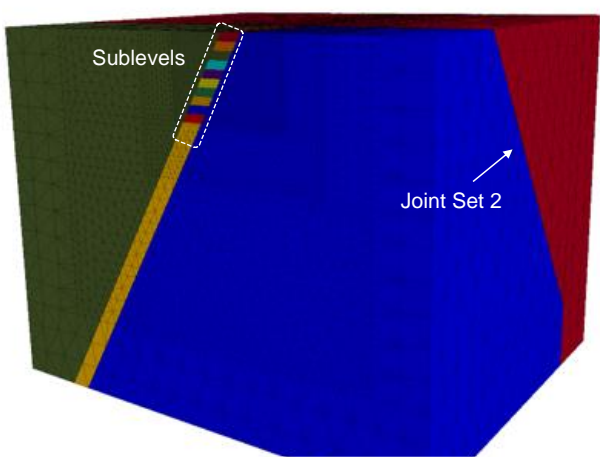

(d)

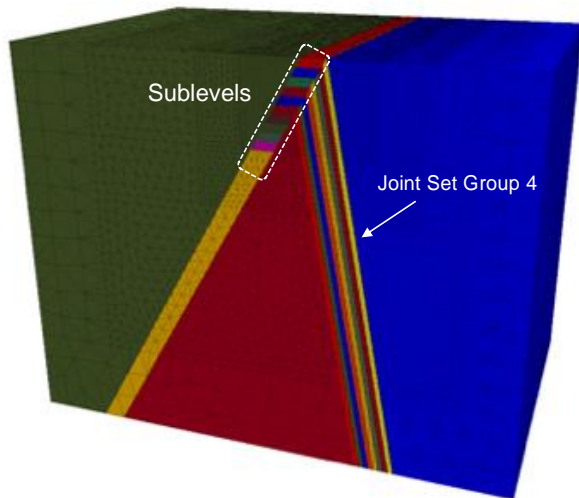

Figure 4: 3DEC models with different major discontinuities group. Please refer to Table 4 for the geometry information of these discontinuities.

Table 5: Discontinuities setup in all cases.

\begin{tabular}{|c|c|c|}
\hline Case & Strike & Dip angle \\
\hline A & $0^{\circ}$ & $60^{\circ}$ \\
\hline B & $90^{\circ}$ & $55^{\circ}$ \\
\hline C & $270^{\circ}$ & $75^{\circ}$ \\
\hline D & $180^{\circ}$ & $80^{\circ}$ \\
\hline
\end{tabular}




\section{Results and Discussion}

The progressive mining by sublevel caving method was simulated in the mine-scale models and the response of each major discontinuity/joint with different orientations in the footwall was obtained and investigated. The unstable and stable slip failure was examined by investigating if there is a sudden increase of shear displacement along with a momentary drop of shear stress along the major discontinuity/joint.

\subsection{Case A}

In case $A$, the major joint was parallel with the contact between orebody and footwall and was $20 \mathrm{~m}$ shift from the orebody-footwall interface. A series of monitoring points were evenly distributed along the joint and located in the same elevation of each excavated level of the ore. The distribution of these monitoring points is shown in Figure 5.

(a)

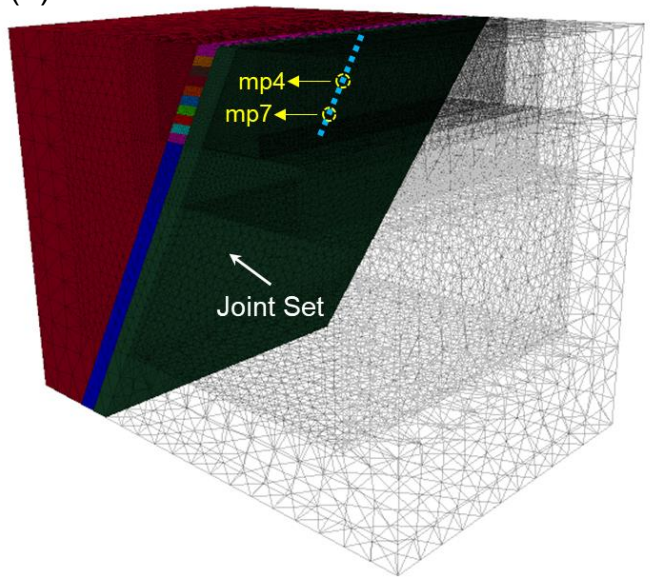

(b)

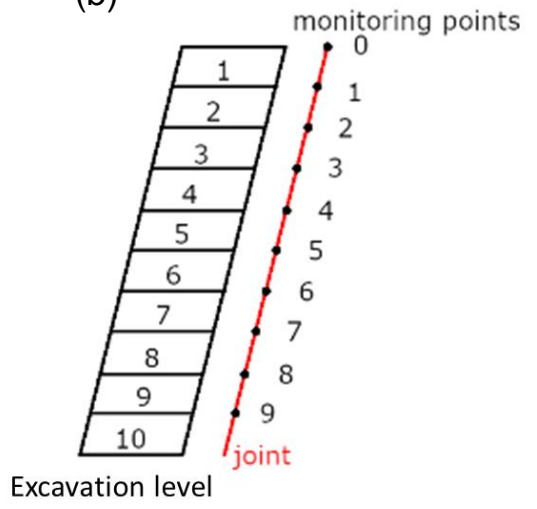

Figure 5: The distribution of the joint set and monitoring points setup for Case A. The monitoring point $\mathrm{mp} 4$ and the monitoring point $\mathrm{mp} 7$ are selected as examples to exhibit the shear stress and shear displacement with excavating these sublevels.

It was observed that the joint yielded at several monitoring points during the excavation process, leading to a sudden increase of shear displacement and the corresponding sharp drop of shear stress. For example, the 4th monitoring point $\mathrm{mp} 4$, following the excavation of 4th level, experienced a significant growth in shear displacement and a remarkable decrease of shear stress at the same time step. This phenomenon signifies that an instant shear slip was triggered due to the influence of excavations. At this monitoring point, the shear strength of this joint 
was overcome and it then yielded during the slip process. Once the shear slip process halted by a resistance force, the system started to reach a new balance in the geomechanical perspective. The shear stress and shear displacement returned to a positively correlated relationship that existed previously before the initiation of shear slip.

We also found other monitoring points at the joint that behaved in a very similar fashion with the 4th monitoring point $\mathrm{mp} 4$. It was characterized that significant changes of shear stress and shear displacement at the 7th monitoring point were triggered after the excavation step 7 (E7). Figure 6 indicates the pattern of shear stress and shear displacement at the 7th monitoring point $\mathrm{mp} 7$ affected by excavations, implying that the $\mathrm{CY}$ joint model delineates the response of the joint, especially the behavior after yielding. Most other monitoring points, which were examined after the excavations of their adjacent levels, were found with very similar pattern as that characterized for the 4th and 7th points.

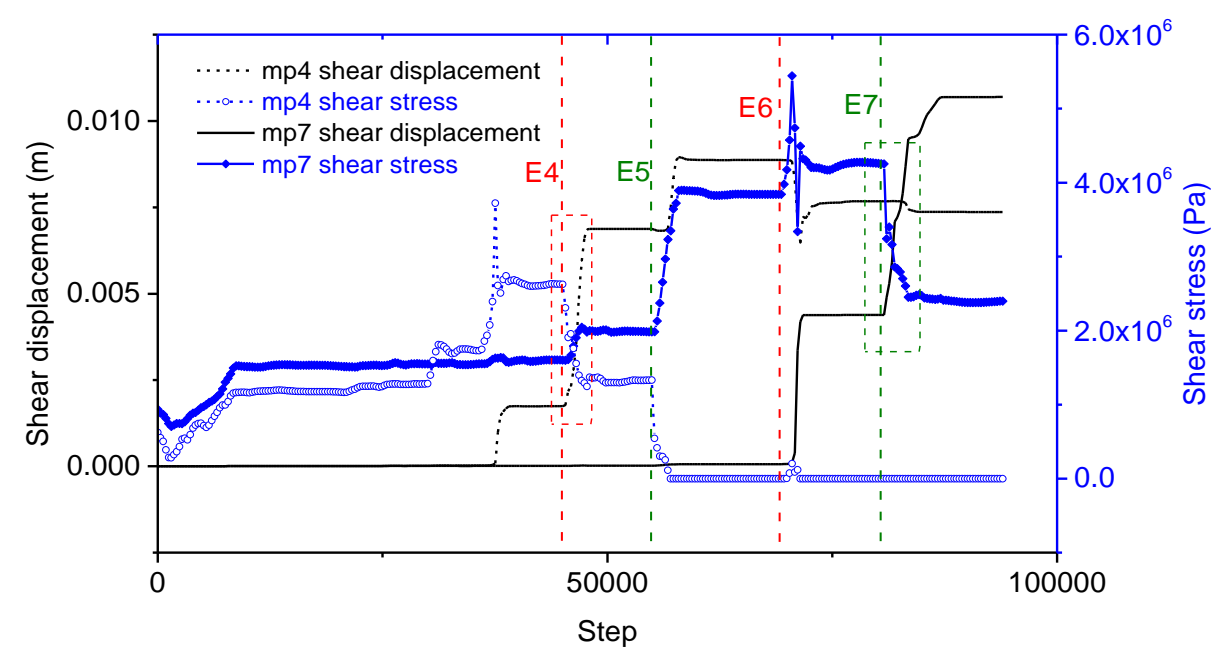

Figure 6: The response of shear stress and shear displacement at mp4 and mp7 in Case A. The signatures of shear slip behaviours are noted by rectangles in dash lines for $\mathrm{mp} 4$ and $\mathrm{mp} 7$, respectively.

\subsection{Case B}

In Case B, the joint group B was assigned in the numerical model. Identical material properties and initiation conditions were applied in the model. The response of a series of monitoring points (blue rectangles in Figure 7) placed in the model was examined. 
(a)

a)

(c)

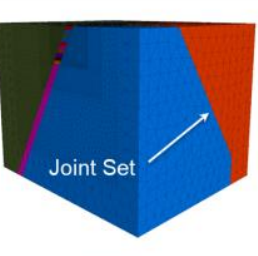

(b)

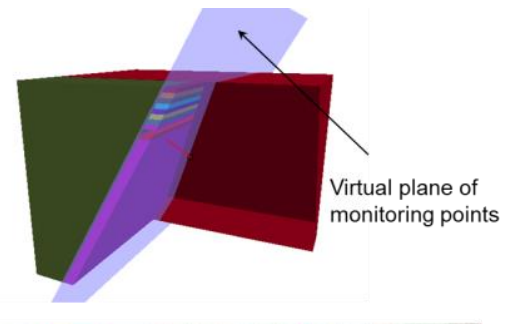

(d)

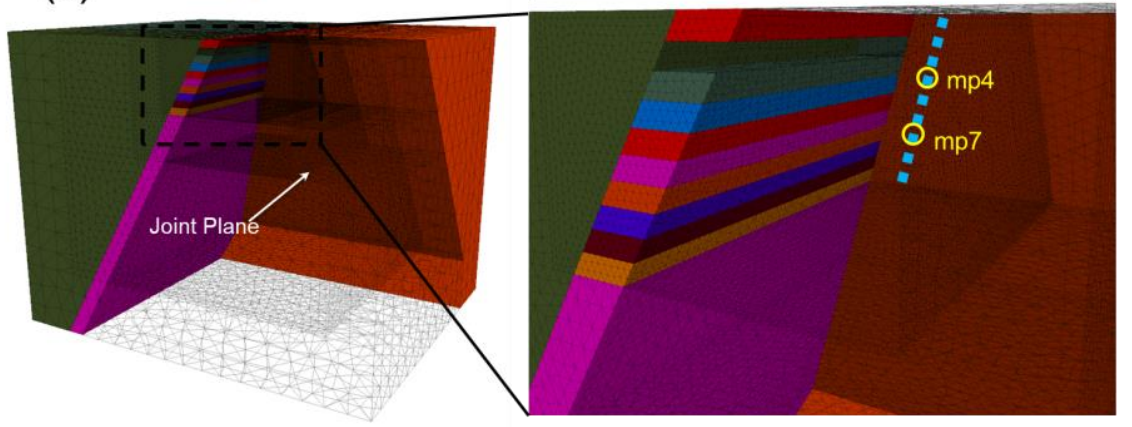

Figure 7: The distribution of the major joint set and monitoring point setup for Case B: (a) the structure of the major joint and blocks; (b) monitoring points are set up along the intersection line of the virtual plane and the joint plane; (c) relative positions of sublevel caving blocks and joint plane; and (d)

distribution of monitoring points. Monitoring points are shown by blue rectangles and are placed in the center of the joint.

As shown in Figure 8, the shear stress and shear displacement of mp4 followed a stable evolution process throughout all excavations because $\mathrm{mp} 4$ was located in the shallow level of mining (Figure 8a). For the monitoring point $\mathrm{mp} 7$ in greater depth, it experienced sudden change of shear stress and shear displacement (Figure 8b). This particular behavior of the 7th monitoring point $\mathrm{mp} 7$ verifies that shear slip was triggered by the excavation of the 7th level and the post-peak softening response was recorded using the $\mathrm{CY}$ joint model. 
(a)
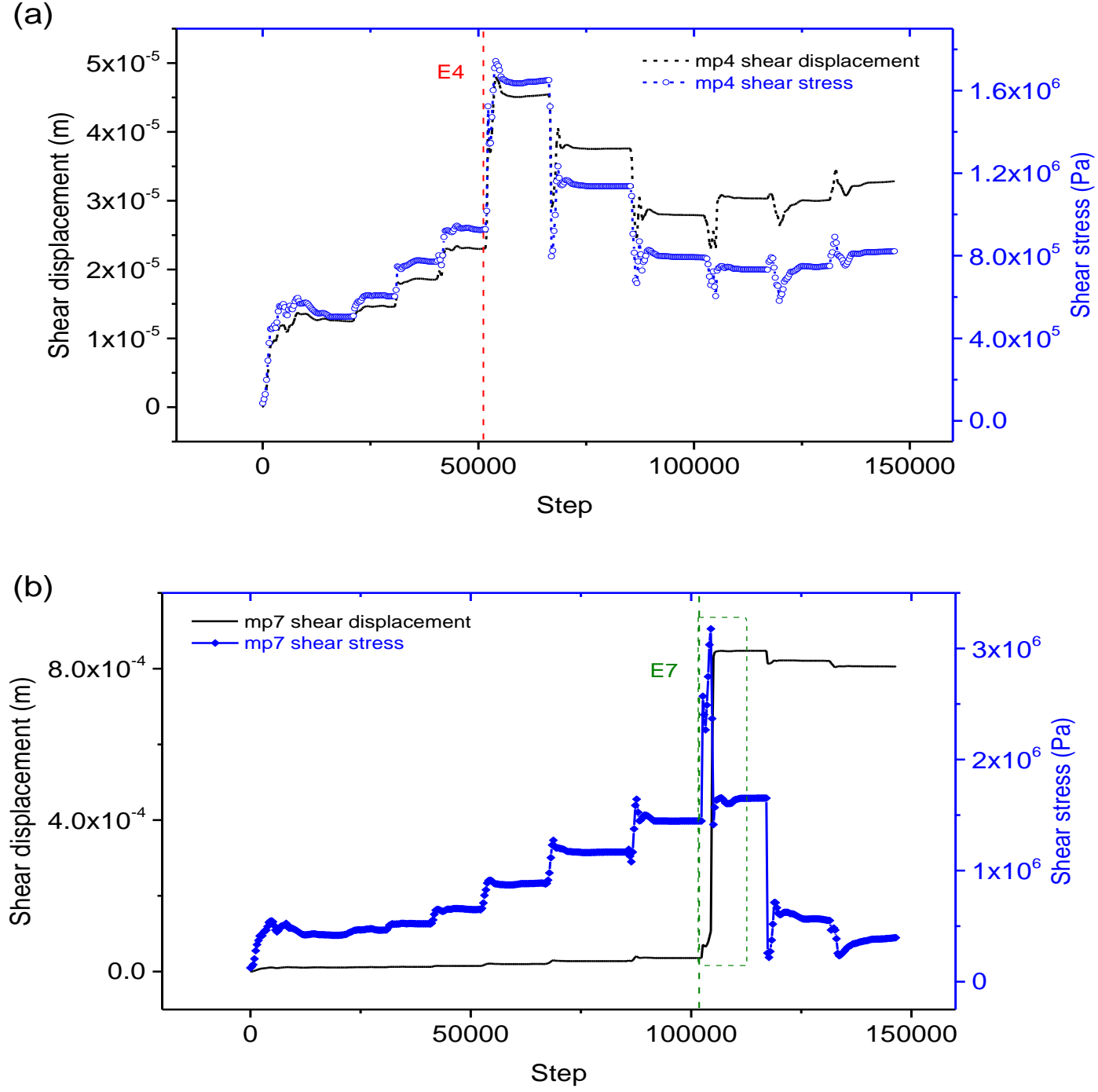

Figure 8: The response of shear stress and shear displacement at (a) $\mathrm{mp4}$; and (b) $\mathrm{mp} 7$ in Case B. The elastic relationship governs the mechanical response of $\mathbf{m p 4}$, while the signature of shear slip behavior is found for $\mathbf{m p 7}$.

We compared the shear displacement and shear stress of monitoring points in response to excavations of Case A and Case B. The major difference was that Case A had a significantly larger shear displacement than Case B. Accordingly, shear stress of Case A was larger than Case B. This phenomenon indicates that unstable shear slip of geological structures is more likely to be triggered in Case A than Case B. More energy from Case A was released suddenly with larger shear stress drop and shear displacement increase. 


\subsection{Case $\mathrm{C}$}

The joint set at Case $\mathrm{C}$ was structured as almost identical with the joint set at Case $\mathrm{B}$ except that the dip direction of the joint set at Case $\mathrm{C}$ is reverse comparing with the joint set at Case B. The setup of monitoring points is shown in Figure 9. In contrast with Case B (Figure 8), no monitoring points was found to reach the regime that was governed by yielding criterion, and all of them lacked post-peak behaviors during all excavations. As shown in Figure 10, the 4th monitoring point mp4 and the 7 th monitoring point $\mathrm{mp} 7$ presented elastic behavior. The shear displacement raised steeply associated with a pronounced shear stress increase at the same step after the excavation of the level. Evolutions of shear displacement and shear stress showed an identical pattern, implying that the relationship of them was very close to elastic.

(a)

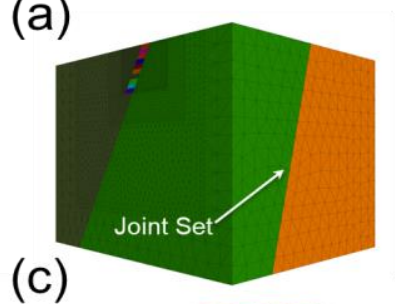

(b)

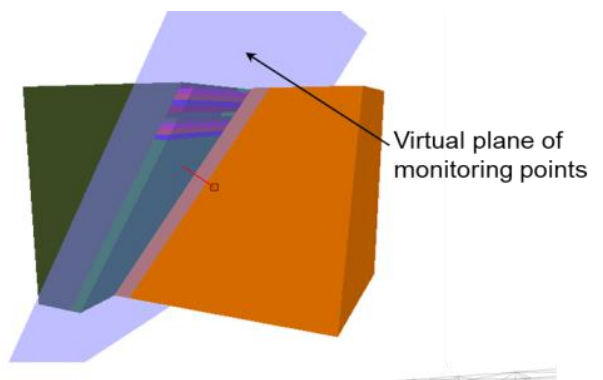

(d)

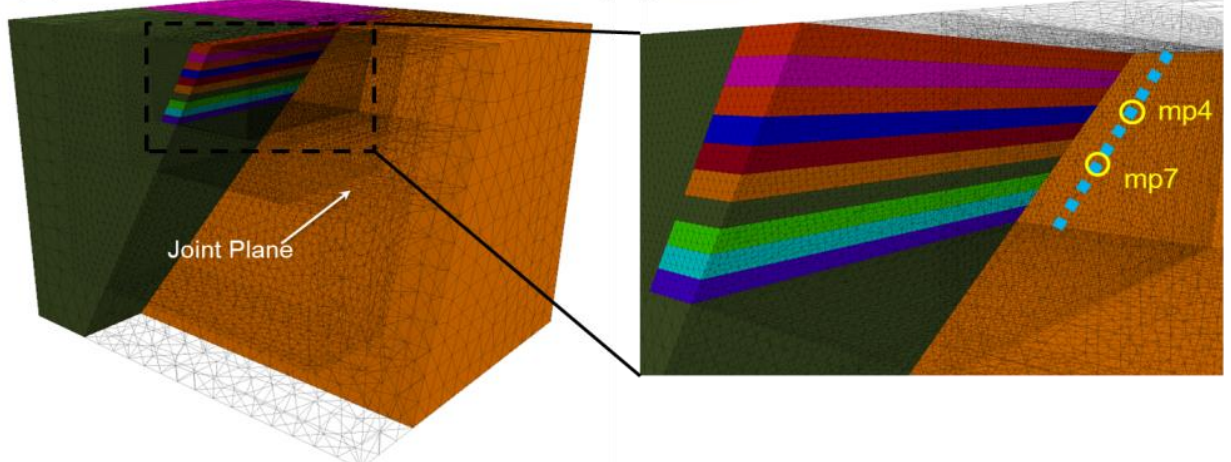

Figure 9: The distribution of joint set and monitoring points setup for Case C:

(a) the structure of the major joint and blocks; (b) monitoring points are set up along the intersection line of the virtual plane and the joint plane;

(c) relative positions of sublevel caving blocks and joint plane;

and (d) distribution of monitoring points. Monitoring points are shown by blue rectangles and are placed in the center of the joint.

In addition to the qualitative comparison between Case B (Figure 8) and Case C (Figure 10), we further quantitatively compared the amplitude of shear stress and shear displacement in Case B and Case C. It was found that amplitudes of them in Case $\mathrm{C}$ were significantly smaller than Case B. Considering the pre-peak elastic behavior and fairly small amplitudes in shear stress and shear displacement, we concluded that Case $\mathrm{C}$ was in a safer scenario than Case B. After examining the 
response of shear displacement and shear stress of all other monitoring points, we found that these monitoring points were characterized in the pre-peak regime throughout all excavations and generally agreed well with the pre-peak elastic relationship. All other monitoring points behaved in a very similar manner with $\mathrm{mp} 4$ and mp7 except the amplitude of shear stress and shear displacement. A monitoring point located in a greater depth experienced larger shear stress and shear displacement due to the increased stress level at depth. The shear stress and shear displacement of these monitoring points were positively correlated, indicating that no shear slip occurred in the vicinity of these monitoring points.

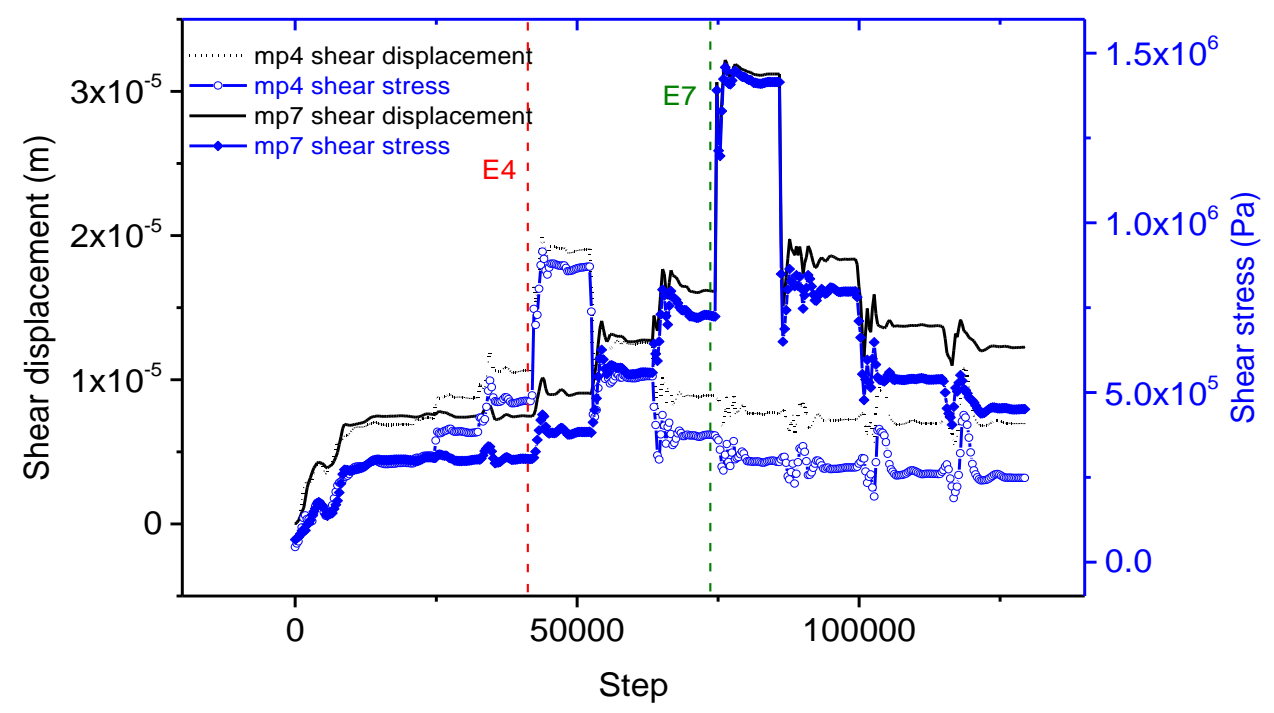

Figure 10: The response of shear stress and shear displacement at mp4 and mp7 in Case C.

\subsection{Case D}

The joint set of Case D dipped toward the opposite direction of that of Case A. In this case, we set up a group of joint sets rather than a major joint which was used in previous cases. The objective of these models is to investigate the effects of mining operations at different depths and the interactions of excavations with joints of different strike and dips. Since the dipping directions of orebody were fixed, the joints needed to be adjusted to adapt for reflecting the relative positions of joints to the orebody. Having multiple parallel joints sets enabled that spatially distributed relationships between monitoring points with sublevel caving blocks were aligned with previous cases. By setting up a group of monitoring points at multiple joints and examining their geomechanical responses affected by excavations (Figure 11), we found that several monitoring points exceeded the yield point, reached the postpeak regime, and experienced strain-softening behavior. 
(a)

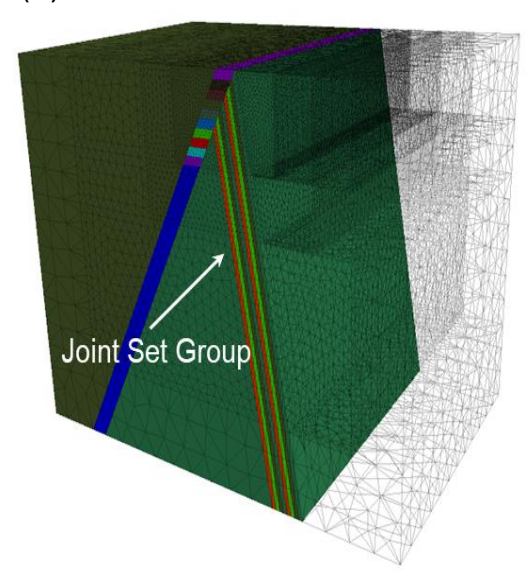

(b)

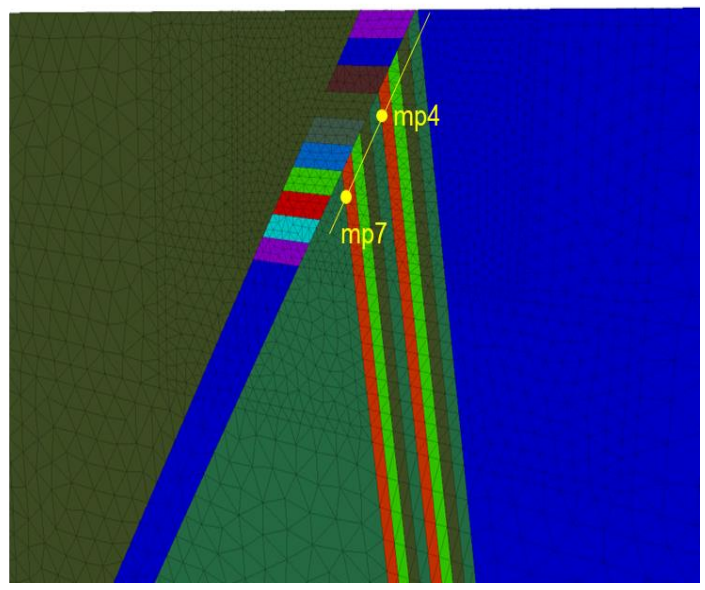

Figure 11: The distribution of joint set and monitoring point setup for Case D. A group of joint sets are setup rather than using a single joint set because these monitoring points need to be at joints and they also need to be spatially parallel to the interface between orebody and footwall.

With the excavation of 5th level, we identified another significant increase in shear displacement and its corresponding shear stress drop at the 4th monitoring point mp4 (Figure 12a). The 5th excavation resulted in larger amplitudes of shear stress drop and shear displacement increase than the 4th excavation at the 4th monitoring point mp4. 
(a)
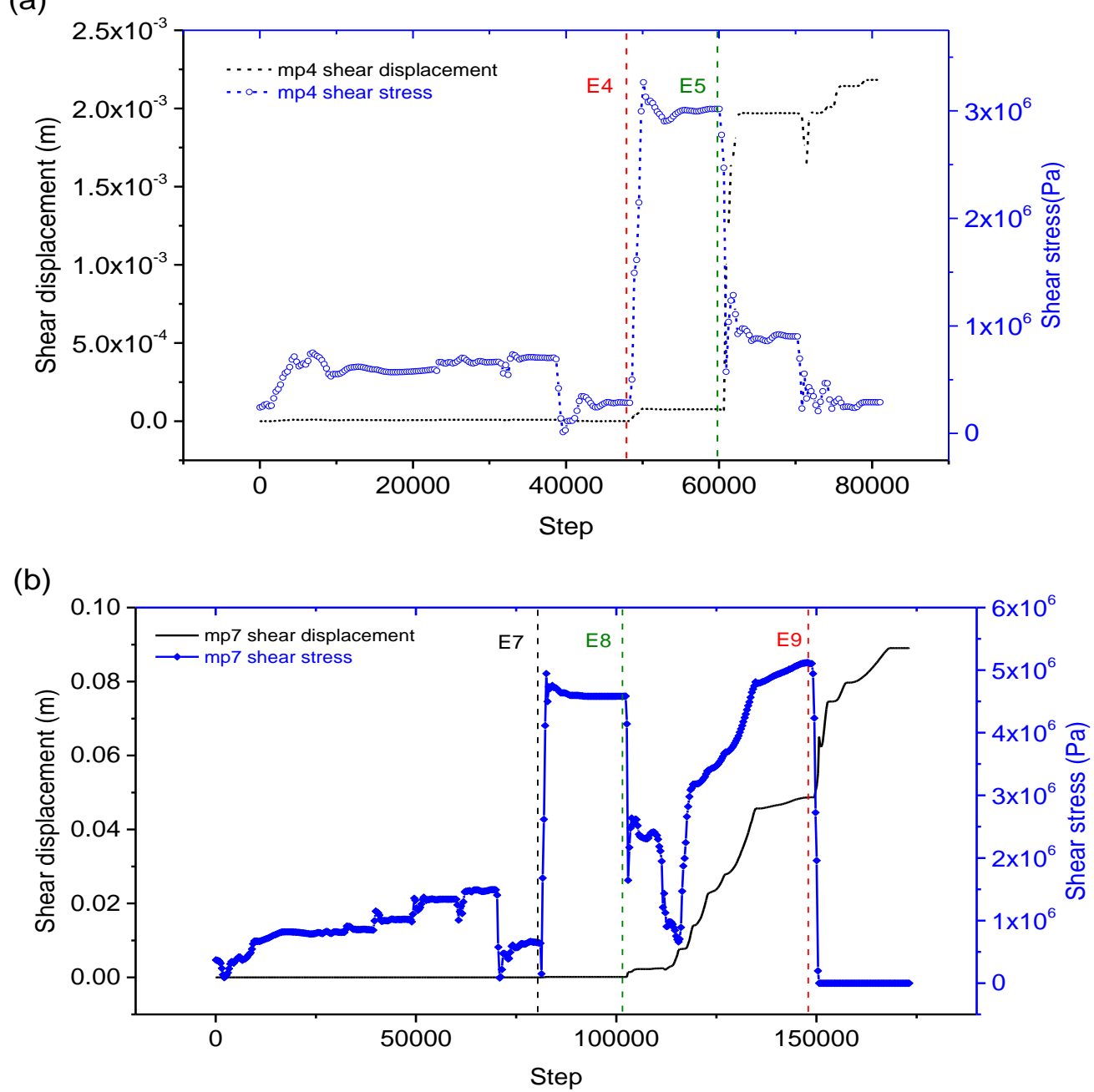

Figure 12: The response of shear stress and shear displacement: (a) at mp4; (b) at mp7 in Case D.

The shear slip behavior at the 7th monitoring point appeared after excavation of the 8th level (Figure 12b). This pattern implied that shear slip was triggered at the monitoring point $\mathrm{mp} 7$ when excavating the deeper levels including E8 and E9. The strain-softening characteristic at the 7th monitoring point mp7 suggested that the joint had been subjected to large movement due to loss of confinement. All monitoring points experienced a great amount of shear stress increase affected by E8 and E9. A possible explanation is that multiple parallel joints lost constraint force in the regime after excavating the 7th level. The interaction of these parallel joints might have a 'domino' effects so that an excavation in a deep level significantly affected all joints above it and posed a very similar influence.

According to summarizing results of stress decrease and displacement increase (Table 6), we found that, for the same case, a deeper excavation resulted in a larger 
amplitude of stress decrease and displacement increase on the nearby monitoring points. It can be inferred that the mining depth is a critical factor determining the amplitude of shear slip behavior for the same distribution of discontinuities. However, a straightforward correlation between the observed maximum magnitude and increased studied time period was not found for the three studied blocks in the literature (Dineva and Boskovic, 2017). Considering mining is a continuous progress, the mining depth is increasing with the increase of time period. Therefore, it implies that the magnitude of a seismic event is not only related to the mining depth. Some other factors also affect the seismicity e.g. geometry of orebody, geomechanical properties of rock mass, geological structures. Associated with the occurrence of seismic events at the Kiirunavaara mine, the average apparent stress drop was 9.28 MPa. The stress change from the CY modeling showed that the maximum stress decrease of $\mathrm{mp} 7$ is $3.89 \mathrm{MPa}$. A likely explanation for this difference is that the depth of modeling mining operation was less than $300 \mathrm{~m}$, but the locations of analyzed seismic events were deeper than $1000 \mathrm{~m}$. Further study is needed to investigate the effect of deeper mining operation on apparent stress drop. Based on the simulation using the mine-scale conceptual numerical model and analyses, the important influential factors on seismicity contributing to unstable slip failures in sublevel caving mining conditions were then identified and qualitatively compared with field observations. It is often observed from the numerical modelling that unstable slip failure of discontinuities with large shear stress drop and shear displacement increase occurs just after excavating the corresponding level where monitoring points are located or level below. A previous study on seismic data found that fault-slip events were concentrated around the production levels and slightly below them (Nordström et al., 2017). Another previous numerical study of the Kiirunavaara Mine suggested that the stress perpendicular to the ore body increases with the vertical distance from the mining level and reaches a maximum (at the footwall drift position) around 35-60 m below the mining level (Malmgren and Nordlund, 2008). Another statistical study concluded that the most significant static stress drop caused by the shear slip was around and below the production on the footwall side (Dineva and Boskovic, 2017). They both supported the conclusion drawn from the numerical simulation. Additionally, it was pointed out that $90 \%$ of the events were located in the footwall, close to the ore contact (Nordström et al., 2017). Our study proved that the discontinuities near the interface between the footwall and the ore are subjected to unstable slip failure. 
Table 6: The stress decrease and the shear displacement at the monitoring point 4 (mp4) and the monitoring point 7 (mp7).

\begin{tabular}{|c|c|c|c|c|}
\hline \multirow{2}{*}{ Case } & \multicolumn{2}{|c|}{ mp4 } & \multicolumn{2}{c|}{ mp7 } \\
\cline { 2 - 5 } & $\begin{array}{c}\text { Displacement increase } \\
(\mathrm{mm})\end{array}$ & $\begin{array}{c}\text { Stress decrease } \\
(\mathrm{MPa})\end{array}$ & $\begin{array}{c}\text { Displacement increase } \\
(\mathrm{mm})\end{array}$ & $\begin{array}{c}\text { Stress decrease } \\
(\mathrm{MPa})\end{array}$ \\
\hline $\mathbf{A}$ & 5.13 & 1.34 & 6.33 & 1.92 \\
\hline B & 0.02 & -0.78 & 0.82 & 1.76 \\
\hline $\mathbf{C}$ & 0.01 & -0.44 & $1.54 \times 10^{8}$ & -0.73 \\
\hline D & 1.90 & 2.73 & 48.53 & 3.89 \\
\hline
\end{tabular}

It is admitted that there are inevitable limitations in this study. Given that the purpose of this study is to investigate the instability caused by the discontinuity, the elastic model was used for major blocks. The footwall, the hanging wall, and the ore were assigned with an elastic model rather than an elastic-plastic strain softening model in order to better indicate the property and performance from the CY joint model. In the same manner, we only applied the CY joint model in the major discontinuity for each case. All other joints were assigned with an elastic joint model. In addition, in order to achieve a balance between the computational time and the high-resolution analysis, we tended to use a relatively simple model in terms of geometry.

\section{Conclusions}

The objective of this study is to develop a numerical modelling methodology for assessing unstable slip potential of discontinuities at deep underground mines. The CY joint model was used to investigate the phenomena observed in direct shear tests with rock joints, such as post-peak softening and dilation. The capability of the numerical codes and its constitutive models in simulating stable and unstable failures under shear loading conditions was verified. The unstable slip failure was successfully simulated by examining the sudden increase of shear displacement along with the momentary drop of shear stress along a discontinuity.

To evaluate the applicability of this numerical modeling methodology in underground mining, the methodology was tested and qualitatively calibrated. In order to test the modelling methodology in a quick and efficient manner, some necessary simplifications were made when constructing the numerical model. The conceptual mine-scale models were built to simulate the mining progress for a sublevel caving configuration, which is employed at the Kiirunavaara mine. Monitoring points were set close to a major discontinuity or a set of discontinuities, which were evenly distributed along the discontinuity/discontinuities and located in the same elevation of each excavated level of the ore. The response of the discontinuities in the footwall was examined by means of the monitoring points. In addition, geological investigation conducted around Block 30, 34 and 38 in levels 1079-1137 $\mathrm{m}$ showed that there are four major groups of fractures distributed in the rock mass in the Kiirunavaara underground mine. To investigate the vulnerability 
of the four groups of fractures to shear slip under mining disturbance, a single fracture representing each fracture group was chosen and implemented in the conceptual numerical model. Parametrical study was conducted by using the conceptual mine-scale numerical models.

In addition, this study showed that location and orientation of geological structures such as discontinuities significantly affect their slip potential. The vulnerability of the four groups of fractures to shear slip under mining disturbance can be ranked as Case A, Case D, Case B, and Case C in a descending order. Case C indicated the stability in the vicinity of the major joint, because the shear stress and the shear displacement of monitoring points were positively correlated and no shear slip behavior was found. In Case B, unstable slip failure of discontinuities is subjected to occur at a deep level compared to a shallow level. In Case A and Case D, unstable slip failure of discontinuities occurs at both deep and shallow level. When it occurs at both levels, it is observed that the shear stress drop and shear displacement increase at discontinuities is higher at the deep level compared to that at the shallow level (Case D) but it is not significant in Case A.

\section{ACKNOWLEDGEMENTS}

The authors gratefully acknowledge the financial support for the projects (Ref. No.: 2017-02213, 2018-04616, 2020-04459) from the strategic innovation programme for the Swedish Mining and Metal Producing Industry (STRIM), which is a joint investment from VINNOVA (The Swedish Governmental Agency for Innovation Systems), the Swedish Energy Agency and Formas. LKAB and Lundin Mining participate in the data collection and continuous discussion with the researchers during the project time. The in-kind support from LKAB and Lundin Mining is greatly acknowledged. LKAB is specially acknowledged for providing funding for the second author to conduct research in the field of ground support design at burstprone ground. 


\section{References}

[1] Salamon, M. (1970). Stability, instability and design of pillar workings. International Journal of Rock Mechanics and Mining Science \& Geomechanics Abstracts, 7(6): 613-631.

[2] Wiles, T. (2002). Loading system stiffness-a parameter to evaluate rockburst. In: Australian Centre for Geomechanics (ed): First International Seminar on Deep and High Stress Mining, 6-8 November 2002. Perth, Australia, p.10.

[3] Aglawe, J. P. (2000). Unstable and violent failure around underground openings in highly stressed ground (pp.3538-3538). Queen's University at Kingston.

[4] Malek, F., Espley, S., Yao, M. and Trifu, C. (2008). Management of high stress and seismicity at Vale Inco Creighton Mine. 42nd US Rock.

[5] Trifu, C. I., Urbancic, T. I. and Young, R. P. (1995). Source parameters of mining-induced seismic events: An evaluation of homogeneous and inhomogeneous faulting models for assessing damage potential. Pure Appl Geophys PAGEOPH 1995;145:3-27. doi:10.1007/BF00879480.

[6] Young, R.P. and Maxwell, S.C. (1992). Seismic characterization of a highly stressed rock mass using tomographic imaging and induced seismicity. $\mathbf{J}$ Geophys Res Earth 1992;97:12361-73. doi:Doi 10.1029/92jb00678.

[7] Ma, X., Westman, E., Slaker, B., Thibodeau, D. and Counter, D. (2018). The b-value evolution of mining-induced seismicity and mainshock occurrences at hard-rock mines. Int. J. Rock Mech. Min. Sci. 2018;104:64-70. doi:10.1016/J.IJRMMS.2018.02.003.

[8] Blake, W. and Hedley, D.G.F. (2003). Rockbursts, case studies from North American hardrock mines, Englewood, Society for Mining, Metallurgy, and Exploration.

[9] Gu, R. and Ozbay, U. (2015). Numerical investigation of unstable rock failure in underground mining condition. Comput. Geotech 2015;63:171-82. doi:10.1016/J.COMPGEO.2014.08.013.

[10] Gu, R. and Ozbay, U. (2014). Distinct element analysis of unstable shear failure of rock discontinuities in underground mining conditions. Int. J. Rock Mech. Min. Sci. 2014;68:44-54. doi:10.1016/J.IJRMMS.2014.02.012.

[11] Manouchehrian, A. and Cai, M. (2016). Influence of material heterogeneity on failure intensity in unstable rock failure. Computers and Geotechnics, 71, pp.237-246.

[12] Cook, N. G. W. (1965). A note on rockbursts considered as a problem of stability. Journal of the South African Institute of Mining and Metallurgy, 65, pp.437-446.

[13] Rice, J. R. (1983). Constitutive relations for fault slip and earthquake instabilities. Pure and Applied Geophysics, 121(3): 443-475.

[14] Garvey, R. J. (2013). A study of unstable rock failures using finite difference and discrete element methods. Ph.D. thesis, Colorado School of Mines, Colorado, USA, p.224. 
[15] Li, K. F. and Heasley, K. A. (2015). Calculating the potential for coal pillar bumps using a local mine stiffness criterion. The 49th US Rock Mechanics/Geomechanics Symposium, ARMA, San Francisco, California, USA, $8 \mathrm{p}$.

[16] Dahner, C., Malmgren, L. and Boskovic, M. (2012). Transition from nonseismic mine to a seismically active mine: Kiirunavaara Mine, in Proceedings Eurock 2012, p.11.

[17] Nordström, E., Dineva, S. and Nordlund, E. (2017). Source parameters of seismic events potentially associated with damage in block 33/34 of the Kiirunavaara mine (Sweden). Acta Geophys., 65: 1229-1242.

[18] Vatcher, J., McKinnon, S. D. and Sjöberg, J. (2014). Mine-scale numerical modelling, seismicity and stresses at Kiirunavaara Mine, Sweden. In: Hudyma M.R. and Potvin Y. (eds). Proceedings of the Seventh International Conference on Deep and High Stress Mining. Deep Mining 2014. Sudbury,Canada: ACG, 363-376.

[19] Svartsjaern, M., Saiang, D., Nordlund, E. and Eitzenberger, A. (2016). Conceptual numerical modeling of large-scale footwall behavior at the kiirunavaara mine, and implications for deformation monitoring. Rock Mech. Rock Eng. 2016;49:943-60. doi:10.1007/s00603-015-0750-x.

[20] Sjöberg, J., Perman, F., Quinteiro, C., Malmgren, L., Dahner-Lindkvist, C. and Boskovic, M. (2012). Numerical analysis of alternative mining sequences to minimise potential for fault slip rockbursting. Mining Technology, 121(4): pp.226-235.

[21] Cundall, P. A. and Hart, R. D. (1984). Analysis of block test No. 1 inelastic rock mass behavior: Phase 2 - A characterization of joint behavior (Final Report). Itasca Consulting Group Report, Rockwell Hanford Operations, Subcontract SA-957

[22] 3DEC manual (2016). 3DEC (Universal Distinct Element Code), Version 5.0. Minneapolis, MN: Itasca Consulting Group Inc.

[23] Cundall, P. A. and Lemos, J. V. (1990). Numerical simulation of fault instabilities with a continuously yielding joint model. In Fairhurst C (ed.). Rockbursts and Seismicity in Mines, Rotterdam: A. A. Balkema, pp.147-152.

[24] Sandström, D. (2003). State of stress at the Kiirunavaara mine: its significance for rock mechanics analysis. Licentiate Thesis (2003:02), Luleå, Sweden, Luleå University of Technology.

[25] Malmgren, L. and Nordlund, E. (2008). Interaction of shotcrete with rock and rock bolts-A numerical study. Int. J. Rock Mech. Min. Sci., 45: pp.538-553.

[26] Dineva, S. and Boskovic, M. (2017). Evolution of seismicity at Kiruna Mine. In Wesseloo J (ed.): The Eighth International Conference on Deep and High Stress Mining, 28-30 March 2017, Perth, Australia, 125-139. 